\title{
Assessing and Improving User Experience with e-Government Portals
}

\section{Said Elnaffar}

\author{
Computer Science and Engineering Department, School of Engineering American University of
}

Ras al Khaimah (AURAK), Ras al Khaima, UAE; said.elnaffar@aurak.ac.ae

\begin{abstract}
Objectives: Classify e-service functions on Websites or portals in order to prioritize which ones to improve based on their performance and importance as viewed by consumers. Methods/Statistical Analysis: We use the standard SERVQUAL questionnaire to extract the Website consumers' views. Then, we analyse the collected data using the Two Dimensional Mean Value Matrix (TDMVM) by mapping the consumer's perception on a 2D space of function performance-importance. The SERVQUAL questionnaire has been customized to suit the business domain we are experimenting with. Findings: As a proof-of-concept, we applied our methodology to one of the national e-government Websites called Tanmia. The two mean values of performance-importance for the 20 quality-specific questions of SERVQUAL were mapped to the 4 quadrants of the TDMVM. Based on the final projection of the quality questions on the 4-quadrant matrix, a recommendation report has been generated with a course of action for each corresponding quadrant. Application/Improvements: Consumers deserve to express their feedback toward e-services delivered. At the same time, decision makers and Website admins need the right tools that allow them to focus on what matters the most to the consumers in order to fix underperforming functions. We showed a methodology, which combines SERVQUAL and TDMVM, that can pinpoint the areas that need immediate attention and the areas that we do not need to waste resources on fixing them. The methodology should boost consumer satisfaction while rending decision makers working effectively and efficiently by allocating resources at the right functional areas.
\end{abstract}

Keywords: E-Recruitment, Four Quadrants, SERVQUAL, TDMVM, User Satisfaction

\section{Introduction}

Web applications and the Internet have revolutionized the way services are delivered to consumers. In many countries around the world, e-government Web sites have aided the public to directly connect with hundreds of services that are typically encompassed in a main portal ${ }^{1}$.

UAE (United Arab Emirates) is one of the early adopters of e-government systems and services $\frac{2,3}{3}$. According to the United Nation e-Government Survey ${ }^{4}$, UAE is deemed one of the world e-government leaders with very high E-Government Development Index (EGDI) levels.
Tanmia $^{5}$ is one of the prominent e-government portals that is used for recruitment in UAE. It connects job seekers with job opportunities in the private and public sector. The front page of the Tanmia portal (Figure 1) gives an idea about the main services it offers to users. Primarily, it allows job seekers to search for jobs training, and vocational guidance and services, and employers to post opportunities and mine for suitable job candidates.

Like many service-oriented Web sites, Registration is the first step that is needed to be completed in order to access the rest. In this step, job seekers fill in their personal information and career objectives (Figure 2). This

${ }^{*}$ Author for correspondence 


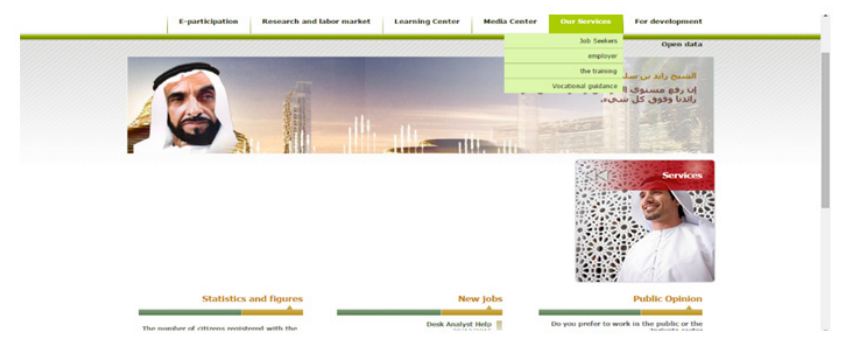

Figure 1. The Tanmia e-recruitment Portal 5 .

step is typically followed by submitting their e-CV. Upon completing those tasks, the entire search tools become available to them. The Tanmia office may then phone the registered users in order to active user registration. The office also encourages them to take advantage of the online available resources such as workshops, interviews, Webinars, psychometric (aptitude) test, and other resources. Likewise, employers from the public and private sector can register and search for job candidates (Figure 3 ). They can specify what documents job seekers are supposed to submit in order to be considered for the job. They follow up on already submitted applications, and can look up the available pile of CV's.

One of the pressing questions that Tanmia as an e-government entity and service provider has is whether the users of their portal are satisfied? What can be improved? What areas that are $\mathrm{OK}$ and should not change? To that end, we consider the Tanmia portal as a case study where we try to assess user satisfaction and spot design weaknesses by surveying these users and analyzing their responses using the Two-Dimensional Mean Value Matrix (TDMVM) ${ }^{6}$ tool which is commonly used in measuring and monitoring product/service quality across various industries -11 . We use the well-known SERVQUAL ${ }^{12}$ as a survey model in order to glean the perception of users towards the quality of service provided to them. SERVQUAL typically measures 22 service attributes that fall into 5 dimensions: reliability, assurance, tangibles, empathy and responsiveness. These dimensions can be applied to any service domain and hence we use it here, with a slight customization, to assess the quality of an online Web site.

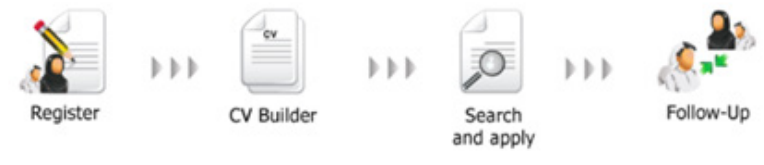

Figure 2. The Registration process for a job seeker.

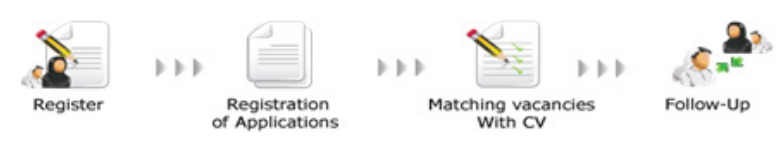

Figure 3. The Registration process for an employer.

\section{Methodology}

For data gathering, we used the modified SERVQUAL to evaluate users' attitude towards the online services with respect to two dimensions: satisfaction, where "1" being "Very Dissatisfied" and "5" being "Very Satisfied", and importance, where "1" being "Not Important" and "5" being "Very Important". The survey starts off with a demographic set of questions that collect information germane to age, gender, and level of education. This part is followed by 20 questions that focus on evaluating the quality of service from different aspects.

To facilitate the distribution of the survey data, we used the online Survey Monkey tool ${ }^{13}$ to conduct our questionnaires online. Before the deployment to the real participants, we tested the survey on some volunteers in order to capture any pitfalls as early as possible. The data collection process took two weeks to complete in order to ensure a maximal sample size.

In fact, our experimentation is not sensitive to the sample size of data collected because we merely wish to demonstrate the applicability our methodology to a real Web site - We are not attempting to validate any phenomenon or a hypothesis from the data.

For analysis, we use the TDMVM tool to measure the service quality of our Web site as it has been applied to many other studies around the world to measure the consumer satisfaction with a service or good. Specifically, we used the TDMVM to capture the perception of users germane to importance and performance levels in a two dimensional space of $\mathrm{X}$-axis (importance) and Y-axis (performance). As shown in Figure 4, each quadrant in this importance-performance grid has a semantic whose interpretation leads to a corresponding action strategy, as explained in the Analysis section below.

\section{Results}

Data were collected via questionnaires implemented using Survey Monkey ${ }^{13}$. Email invitations were sent to 


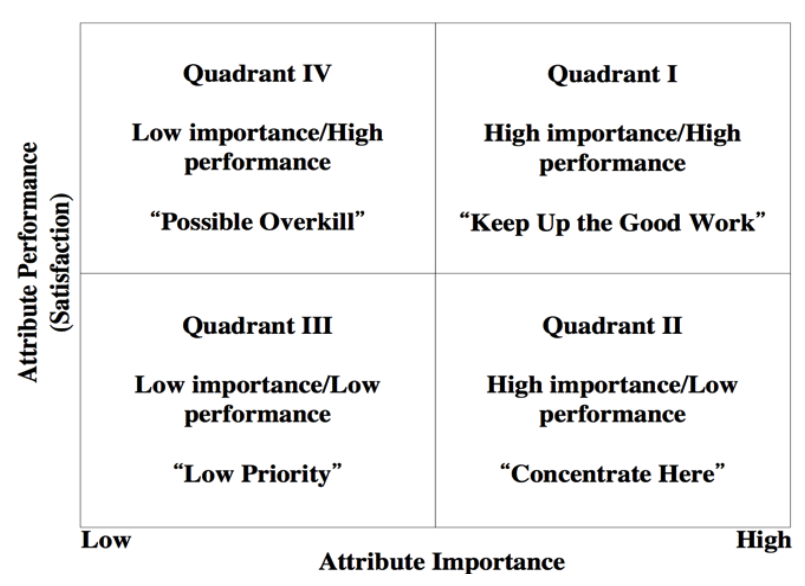

Figure 4. The 4 Quadrants of a Two Dimensional Mean Value Matrix.

all Tanmia registered users from the period of December 29, 2015 until January 14, 2016. We got 186 questionnaires filled out. The demographic data showed that females constituted $86.34 \%$ of the respondent sample, and people over 22 years old accounted for $91.67 \%$. Respondents with high school degrees (49.45\%) and bachelor degrees (48.9\%) were majority while postgraduate degrees $(1.10 \%)$ and primary school graduates $(0.55 \%)$ were minority.

For each SERVQUAL attribute (question), we computed the average of satisfaction and importance as perceived by users. We also computed these averages for the overall dimension that encompasses each group of attributes.

Table 1 shows that the highest satisfaction is towards "18. Providing Job Seekers with mail" (mean=3.4286) and "15. Assuring the confidentiality of personal data" (mean $=3.9628)$, while the lowest satisfaction is towards "14. Searching for the ideal job quickly" (mean $=3.1298)$. The lowest importance was towards "1. Inquiring about online job opportunities quickly" $($ mean $=3.2735)$. The overall importance scored a mean of 3.3615 while the overall satisfaction scored a mean of 3.4046 .

\section{Analysis}

Using the two dimensions of satisfaction and importance (Figure 5), we mapped the mean values of each attribute of the TDMVM in order to extract the meaning of each quadrant as follows:

- Quadrant I (High importance/High performance) - Items 4, 7, 8, 9, 15, 16, 17, 18, 19, 20, 22 and 24

Table I. Average User Satisfaction and Importance against Each SERVQUAL Question

\begin{tabular}{|c|c|c|c|c|}
\hline Assessed Dimension & Service Attribute & Impor & rtance S & Satisfaction \\
\hline & $\begin{array}{l}\text { 1. Inquiring about online job opportunities } \\
\text { quickly }\end{array}$ & & 3.2735 & 3.2078 \\
\hline & 2. Information richness on the web & & 3.2886 & 3.6863 \\
\hline \multirow[t]{5}{*}{ 21. Tangibles } & 3. Browsing the web easily & & 3.3294 & 3.6286 \\
\hline & $\begin{array}{l}\text { 4. Executing Web Service Function } \\
\text { Operations easily }\end{array}$ & & 3.3774 & 3.6262 \\
\hline & $\begin{array}{l}\text { 5. Providing online information for } \\
\text { manufacturers }\end{array}$ & & 3.3176 & 3.4340 \\
\hline & & Average & 3.3173 & 3.5166 \\
\hline & 6. Providing a 24-hour assistance service & & 3.3084 & 3.3458 \\
\hline \multirow[t]{5}{*}{ 22. Reliability } & $\begin{array}{l}\text { 7. Responding immediately after resume } \\
\text { registration }\end{array}$ & & 3.4009 & 3.4567 \\
\hline & $\begin{array}{l}\text { 8. Providing a speedy and steady web } \\
\text { browser }\end{array}$ & & 3.3886 & 3.5880 \\
\hline & $\begin{array}{l}\text { 9. The web cannot shutdown suddenly } \\
\text { while inputting data }\end{array}$ & & 3.3918 & 3.7204 \\
\hline & & Average & 3.3725 & 3.5277 \\
\hline & $\begin{array}{l}\text { 10. Responding accurately to a user's } \\
\text { problem }\end{array}$ & & 3.3405 & 3.5139 \\
\hline \multirow[t]{4}{*}{ 23. Responsiveness } & 11. Being a good custom claim provider & & 3.3542 & 3.5116 \\
\hline & 12. Responding quickly to a user's problem & & 3.3524 & 3.4608 \\
\hline & & Average & 3.3490 & 3.4954 \\
\hline & 13. Providing high-accuracy job matching & & 3.3437 & 3.2762 \\
\hline \multirow[t]{5}{*}{ 24. Assurance } & 14. Searching for the ideal job quickly & & 3.3381 & 3.1298 \\
\hline & $\begin{array}{l}\text { 15. Assuring the confidentiality of personal } \\
\text { data }\end{array}$ & & 3.4207 & 3.9628 \\
\hline & $\begin{array}{l}\text { 16. Assuring the accuracy of job } \\
\text { opportunities and information }\end{array}$ & & 3.3693 & 3.4695 \\
\hline & & Average & 3.3679 & 3.4596 \\
\hline & $\begin{array}{l}\text { 17. Providing job seekers with a call center } \\
\text { for hiring }\end{array}$ & & 3.3848 & 3.4722 \\
\hline \multirow[t]{4}{*}{ 25. Empathy } & 18. Providing job seekers with mail & & 3.4286 & 3.7837 \\
\hline & $\begin{array}{l}\text { 19. Providing an online call Center (Web } \\
\text { Services) }\end{array}$ & & 3.3907 & 3.6763 \\
\hline & 20. Contacting with call Center is easy & & 3.4234 & 3.7115 \\
\hline & Total Average & Average & $\begin{array}{l}3.4069 \\
3.3615\end{array}$ & $\begin{array}{l}3.6609 \\
3.5329\end{array}$ \\
\hline
\end{tabular}

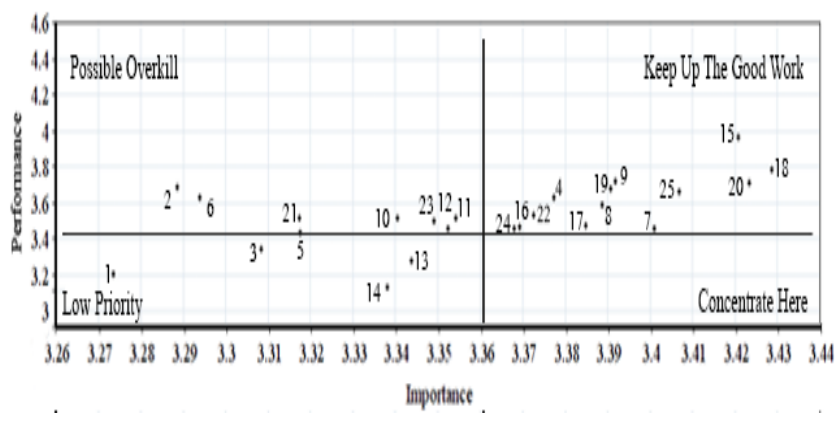

Figure 5. TDMVM with attributes ratings for the Tanmia portal. 
fell within "Keep Up the Good Work", which implies that these are highly important services and that job seekers are highly satisfied with them. Business administrators and Web site managers should keep up the good work in those areas.

- Quadrant II (High importance/Low performance) - This is classified as "Concentrate Here", which indicates that these services are of high importance while job seekers' satisfaction is low. Business administrators and Web site managers should deem this quadrant a highly priority and rectify any services that fall into it. Fortunately, we found no services that fall into this category, otherwise the administration has some serious work to do.

- Quadrants III (Low importance/Low performance) - Items 1, 3, 13 and 14 are classified as "Low Priority", which indicates that these services are not important to the costumer regardless how they are performing. Business administrators and Web site managers should not focus on these services.

- Quadrant IV (Low importance/High performance): Items 2, 5, 6, 10, 11, 12, 21, and 23 are recognized as "Possible Overkill" which means that those services are not important however costumers are satisfied with their performance. Business administrators and Web site managers should not pay any attention to those services.

Figure 6 depicts the satisfaction level under some service attributes as perceived by male and female users based on their experience with the Tanmia Web site. It is not hard to notice the discrepancy in rating between genders. A preliminary interview-based investigation with some respondents revealed that each gender tends to have some standard or even bias towards the Web site

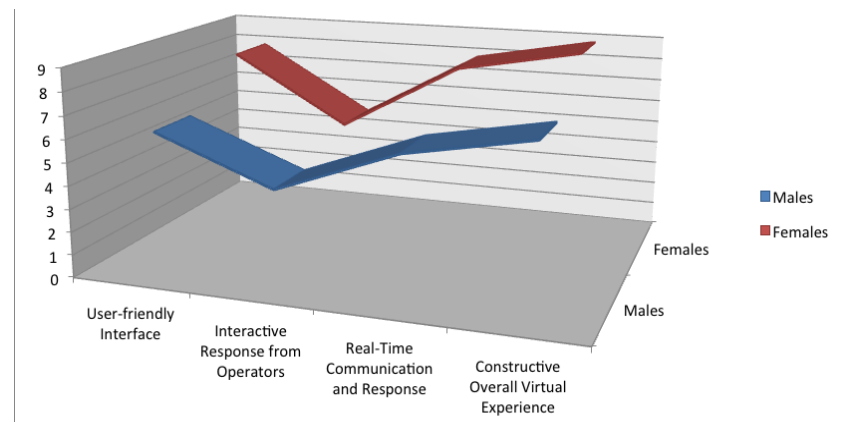

Figure 6. The Male vs. Female user satisfaction level towards some service attributes. design and user interface of the online functions that may have impact on the ratings of satisfaction they gave. Males expressed their focused interest in the usability and graphical user interface of the Web site. Agility of navigation and the intuitive engagement with the online functions seemed to be a higher priority for them. Women, on the other hand, expressed their priority towards the quality of the business functions that being offered and the outcome of each. They also wished to have a better communication means, e.g., live chat, to interact with in case they encounter a problem.

Based on the above statistics, analysis and observations made by interviewing some users, the following recommendations can be made in order to boost the satisfaction rate:

A) The overall layout of the Web site needs attention by having a more attractive theme and design styles.

B) This e-government Web site needs a better communication tool between the site visitor and the back office operators, preferably live chat, in at least two languages.

C) The search function needs to provide more options for filtering results.

D) The matching algorithm needs improvement in order to increase the accuracy of the returned list of CV's.

We trust that improving the e-government portal should foster the trust between the public users (as consumers) and the e-government (as a service provider). Such trust should lead to further expansion of services and winder spread of its adoption.

\section{Conclusion}

In this work, we presented a usability case study for an e-government portal called Tanmia. In order to pinpoint strengths and weaknesses as directly perceived by the online users, we used the SERVQUAL questionnaire which is typically used for collecting data for the purpose of analyzing quality of service. Subsequently, we used the TDMVM matrix to analyze data and detect the concentration of their averages in the two-dimensional space of importance (to the users) and performance (as delivered to the users).

Using this methodology, the decision makers can not only focus on what needs improvement, but also save on what not to be modified. We believe that the outcome of 
this methodology can help the administration take the necessary steps towards improving their services to the public, which intrinsically should boost their satisfaction and trust in future introduced online services.

\section{Acknowledgment}

I would like to thank Fatimah Alzaabi for conducting the surveys used in this work, and the Tanmia administrators for their collaboration.

\section{References}

1. Alenezi H, Tarhini A, Sharma S. Development of Quantitative Model to Investigate the Strategic Relationship Between Information Quality and E-Government Benefits. Transforming Government. 2015; 9(3):324-51.

2. Obeidat O, Saleh A. Al Tamimi \& Company: UAE Officials Declare 2015 'Year of Innovation'. 2015.

3. Abbas W. UAE Ranks Eighth Globally in Broadband Leadership. Emirates. 2010; 24(7).

4. UNPAN. Date Accessed: November 6 2016: Available from: http://workspace.unpan.org/sites/Internet/Documents/ UNPAN96407.pdf.
5. Tanmia. Date Accessed: Sep 12 2016: Available from: https://tanmia.ae/Arabic/Pages/default.aspx.

6. Yang M, Chun et al. Using A Two-Dimensional Mean Value Matrix (TDMVM) To Improve Users Satisfaction With Government E-Recruitment Website. Journal of Software (JSW). 2015; 10(1):82-93.

7. Martilla A, James J. Importance-performance analysis. Journal of Marketing. 1977; 41:77-9.

8. Lo C, Wang C, Chien P, Hung C. An empirical study of commercialization performance on nanoproducts. Technovation. 2012; 32(3-4):168-78.

9. Chang C. Improving employment services management using IPA technique. Expert Systems with Applications. 2013; 40:6948-54.

10. Chen K. Improving importance-performance analysis: The role of the zone of tolerance and competitor performance: The case of Taiwan's hot spring hotels. Tourism Management. 2014; 40:260-72.

11. Coghlan A. Facilitating reef tourism management through an innovative importance-performance analysis method. Tourism Management. 2012; 33(4):767-75.

12. Parasuraman A, Zeithaml V, Berry L. Refinement and reassessment of the SERVQUAL scale. Journal of Retailing. $1991 ; 67(4): 420-50$.

13. Survey Monkey. Date Accessed: Sep 13 2016: Available from: http://www.abet.org. 